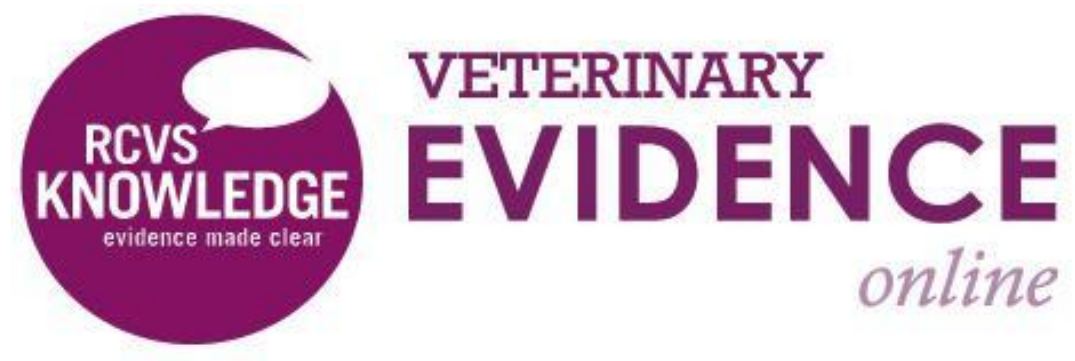

\title{
Epileptic Seizures Versus Syncope: Pathophysiology and Clinical Approach
}

Marios Charalambous DVM, GPCert(Neuro), CSci, FHEA, MRSB, MRCVS ${ }^{1^{*}}$

Sergio A. Gomes DVM, MRCVS ${ }^{2}$

Stella Papageorgiou DVM ${ }^{3}$

Massimo Orioles DVM, CertAVP, MRCVS ${ }^{4}$

\footnotetext{
${ }^{1}$ UCL Institute of Neurology, Faculty of Brain Sciences, University College London, United Kingdom

2 Queen's Veterinary School Hospital, Department of Veterinary Medicine, University of Cambridge,

United Kingdom

${ }^{3}$ Clinique Vétérinaire Advetia, Paris, France

${ }^{4}$ Lida Vets, 33 Lilac road, Cambridge, United Kingdom

Corresponding Author (marios.charalambous.15@ucl.ac.uk)
}

ISSN: 2396-9776

Published: 28 Feb 2017

in: Vol 2, Issue 1

DOI: http://dx.doi.org/10.18849/ve.v2i1.58

Reviewed by: Pete Rodgers and Nieky van Veggel (BSc MSc

PgCert RSci CBiol MRSB EurProBiol FHEA) 
Generalised epileptic seizures and syncope are two syndromes with similar clinical manifestation and their differentiation can be quite challenging. The aim of this review is to use an evidence-based approach in differentiating these two syndromes through the comprehension of the pathophysiological mechanisms involved and their clinical signs. Both syndromes affect regions of the forebrain and consciousness level, although, different mechanisms are involved. Syncope is a paroxysmal event secondary to a short-term decrease in cerebral perfusion, oxygenation or essential nutrients delivery. Generalised epileptic seizure activity is defined as the clinical manifestation of transient paroxysmal disturbances in brain function secondary to an imbalance between excitatory and inhibitory neurotransmitters. Clinical criteria, including precipitating events, clinical signs preceding, during and following the episodes and event duration, can be used to differentiate the two syndromes. Although these criteria might be useful for the practitioner, definite conclusions should be precluded due to the lack of original research articles and weak evidence on this specific field.

Application: The review might be a useful tool for the general practitioner and clinical scientist as it will aid towards the differentiation of two syndromes, i.e. generalised epileptic seizures and syncope, with similar clinical presentation.

\section{INTRODUCTION}

Generalised epileptic seizures and syncope are two syndromes with similar clinical manifestation and their differentiation can be quite challenging. The aim of this review is to provide the clinician with general guidelines on how to differentiate these two syndromes through comprehension of the syndromes' pathophysiology mechanisms and clinical signs.

Syncope is defined as a sudden, transient loss of consciousness and postural tone, originating from a shortterm interruption of blood perfusion, oxygenation or delivery of essential nutrients to the brain. It is characterised by sudden onset, short duration, and spontaneous recovery (Davidow et al., 2001, Folino 2005, Moya et al., 2009). A dog presented with syncope usually collapses suddenly and may experience transient myoclonus or tonic spasms. Micturition and vocalisation may also occur. Pre-syncope is defined as a shorter and/or milder cerebral offence in which the animal does not lose consciousness completely, but may manifest incoordination or hind limb weakness (Wa, 2007). A more severe presentation of syncope can lead to the occurrence of brief tonic-clonic activity (hypoxic convulsive syncope) and results from a diffuse cerebral hypoperfusion, secondary to severe hypotension, cardiac arrhythmia or asystole (Wa, 2007, Lewis et al., 1999).

Generalised epileptic seizures are defined as transient, paroxysmal changes in neurological status or behaviour, secondary to abnormal activity of the cerebral neurons (March, 1998, Podell, 1996). Seizures can affect sensory, motor, and autonomic functions as well as consciousness, cognition and behaviour. This syndrome might initially occur when the animal's level of activity is low (e.g. during sleep). Generalised seizures consist of three sequential phases: pre-ictus (prodrome and aura), ictus, and post-ictus (Berendt et al., 1999). During the pre-ictus, prodromal signs are first seen as subtle manifestations preceding a seizure event and last for minutes, hours or even days or weeks. The prodromal signs consist of behavioural changes and, usually, are not noticed by the owners. The prodrome is followed by the aura, which represents the onset of the seizure (Berendt et al., 1999). During this phase, atypical behaviour and autonomic signs are common 
presentations, including pacing, licking, hiding, attention-seeking, hypersalivation and vomiting. It is followed by the true seizure phase, ictus, which is the most visually impressive event to the owners. Ictus is generally manifested by a loss of consciousness, involuntary muscle movements and tonic-clonic activity and its usual duration ranges from 1 to 3 minutes. On the last stage, post-ictus, unusual behaviour such as disorientation, restlessness, and aggression as well as blindness may be present and can last from seconds to days (March, 1998, Podell, 1996).

Differentiation of these two syndromes can be quite a challenging process in daily clinical practice (Barnett et al., 2010). They share several clinical features and both are sudden and shocking events to the owners. A thorough anamnesis is the first step into distinguishing the two episodes. The precipitating events, clinical signs preceding, during and following the episodes and main event duration can provide the veterinary surgeon with important clues and initiate a diagnostic protocol. Video recording of the event is highly recommended, as it can be a rather helpful tool. However, a relatively recent study showed that video footage should be interpreted with caution (Packer et al., 2015). Precisely, the study found that there was a low level of agreement among veterinarians who were not always able to interpret, based on the videos, whether they could observe an epileptic seizure or another paroxysmal event. Further diagnostic investigation including complete blood count, biochemistry, electrocardiography, holter-monitor, echocardiography, thoracic/abdominal radiographs, brain magnetic resonance imaging (MRI) and encephalography (EEG) are usually vital for a definitive differentiation.

\section{PATHOPHYSIOLOGY}

The main similarity between seizures and syncope is that both affect regions of the forebrain and consciousness level. However, different mechanisms are recruited during each episode that eventually leads to collapse.

\section{Syncope}

Syncope is a paroxysmal event secondary to a short-term decrease in cerebral perfusion, oxygenation or essential nutrients delivery. These changes result in a decreased function of the brain regions responsible for the level of consciousness (Schnipper et al., 2001). Even a short-term shortage in oxygen and glucose may lead to syncope, as the brain has the highest energy demands of all body organs (Tidwell et al., 2011). Syncope can occur when cerebral blood flow (CBF) drops below $50 \%$ or $40 \%$ of the control value leading to a significant fall of CBF (Waelbers et al., 2010). Excitement or strenuous exercise are the most commonly associated triggers in animals (Wa, 2007).

The $\mathrm{CBF}$ is determined mainly by the cerebral perfusion pressure (CPP). The CPP is directly proportional to the balance between mean arterial pressure (MAP) and intracranial pressure (ICP). CPP is also inversely proportional to the brain vascular resistance (BVR) (Davidow et al., 2001, Waelbers, 2010). CBF is kept constant by autoregulatory mechanisms in healthy animals (Folino, 2005). Usage of formulas can simplify the comprehension of these factors (1).

$\mathrm{CPP}=\frac{\text { MAP-ICP }}{\text { BVR }}$ 
MAP depends on the cardiac output (CO), systemic vascular resistance (SVR) and central venous pressure (CVP) (Waelbers et al., 2010). So, the formula can be reformulated (1) as follows:

$$
\mathrm{CPP}=\frac{[(C O x \text { SVR }- \text { CVP })-I C P]}{\text { BVR }}
$$

It becomes clear that any disorders resulting in an increased ICP, CVP, BVR or a decreased CO and SVR can lead to a decrease in CBF. Therefore, syncope may represent an event with multifactorial aetiology (table 1) with several mechanisms being involved. Other factors which can affect CBF include arterial oxygenation, venous outflow, metabolic rate and arterial carbon dioxide tension (Waelbers et al., 2010). Metabolic disorders can trigger a syncopal event, even when CPP is normal (Davidow et al., 2001). Nonetheless, most aetiologies include brain hypoperfusion which results in the loss of consciousness (Folino, 2005). Neurocardiogenic reflexes, in particular orthostatic hypotension which commonly occurs in humans, are rare in animals due to their quadruped stance (Folino, 2005, Wa, 2007).

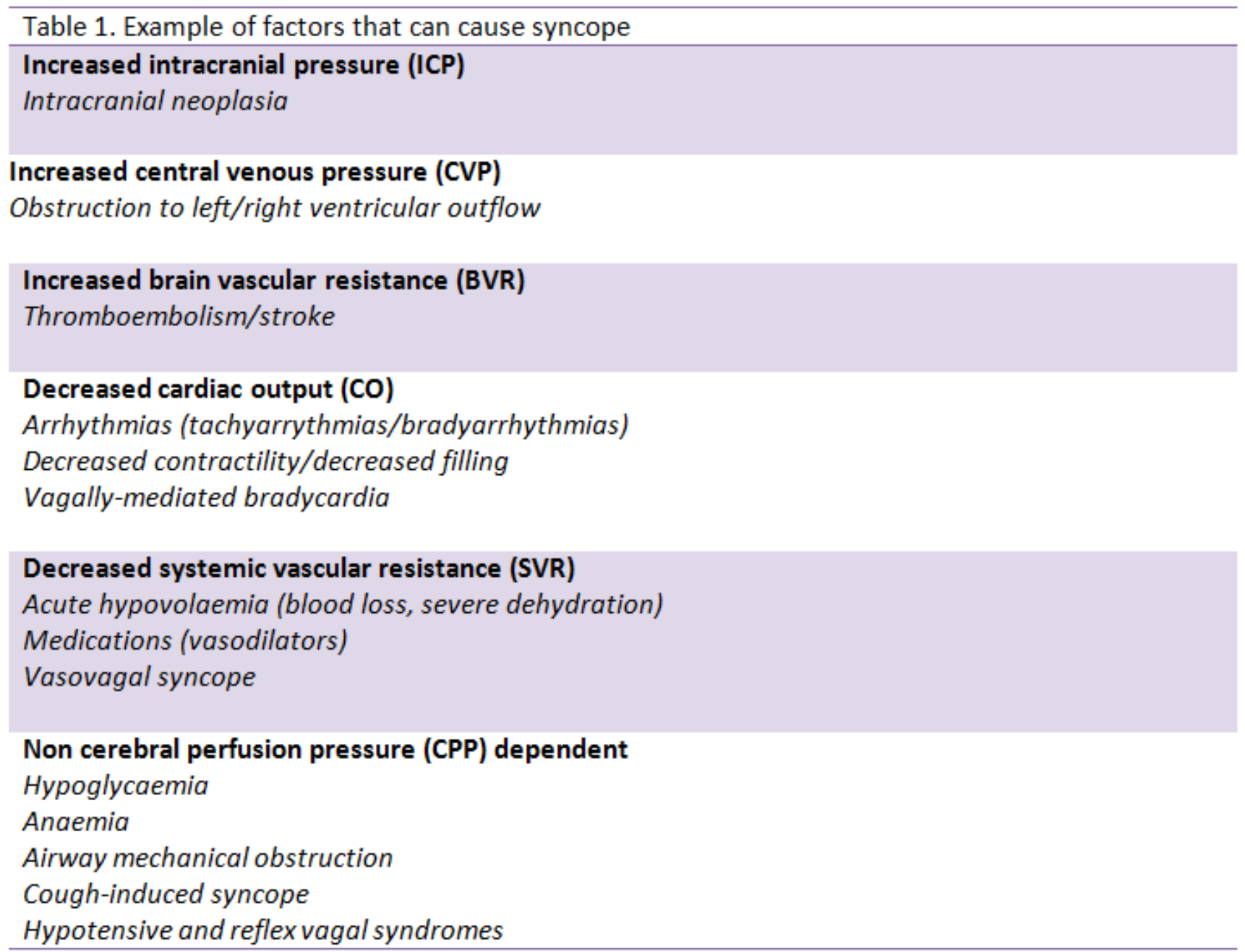




\section{Generalised epileptic seizures}

Seizure activity is defined as the clinical manifestation of transient paroxysmal disturbances in brain function which are caused by an imbalance between excitatory and inhibitory neurotransmission (Fisher et al., 2005). The brain region, within which seizure activity is triggered, is called epileptogenic zone or area (Lüders et al., 2006). In humans, the brain regions that are highly sensitive to develop seizures include temporal lobe structures such as the hippocampus, the amygdala, and the piriform cortex (Aroniadou-Anderjaska et al., 2008). Changes that occur on the epileptogenic zone are poorly understood but are thought to include cell death, axonal growth, reorganisation of neural networks, alterations in the release of neurotransmitters, and neurogenesis (Herman, 2006). These changes cause neurons to become hyperexcitable and can lead to spontaneous seizures (Herman, 2006).

At the neuronal level, seizure activity is characterised by two primary events: hyperexcitability and hypersynchronicity. The hyperexcitability state, as mentioned above, is responsible for the initiation of the seizures. Pathophysiological mechanisms in this state include: 1) altered neuronal membrane function, such as increased permeability, which may occur due to hypoxia or inflammation, 2) decreased inhibitory or increased excitatory neurotransmission mediated, primarily, by gamma-aminobutirric-acid A (GABAA) and glutamate respectively, 3) alteration in number, balance, sensitivity or function of the receptors, such as GABAA or glutamate receptors, and 4) changes in extracellular ions concentration, such as potassium and calcium ions (Boothe, 2001, Aroniadou-Anderjaska et al., 2008, Armijo et al., 2002).

The hypersynchronicity state is characterised by an increased excitability of neighbouring neurons. The neurons are stimulated by the abnormal electrical activation via non synaptic interactions and activation of collateral fibres (Boothe, 2001). Once started, the seizure discharge may synchronise with other neurons and spread into the surrounding areas of the brain. Normally, the spread of seizure can be prevented by a region of surrounding inhibitory neurons (Bromfield et al., 2006). However, this inhibition is surpassed when there is sufficient activation to recruit surrounding neurons (Bromfield et al., 2006). The mechanisms recruited for this state include repetitive discharges that lead to different events such as: 1) increase in extracellular potassium ions tending to depolarize neighbouring neurons, 2) accumulation of calcium ions in presynaptic terminals leading to enhanced neurotransmitter release, and 3) depolarisation-induced activation of the N-methyl-Daspartate (NMDA) receptor causing further calcium ions influx and neuronal activation (Bromfield et al., 2006). Lastly, glial cells play an essential role in buffering functions that balance the uptake of potassium ions and glutamate; alteration of these functions may cause hyperexcitability (Rogawski, 2005). There is also evidence that a paroxysmal depolarising shift (PDS) can be generated by the release of glial excitatory neurotransmitters. Even in the absence of synaptic interactions, glial (astrocytic) release of glutamate can trigger PDS-like events (Rogawski, 2005).

\section{DIFFERENTIATION BASED ON CLINICAL PRESENTATION}

Although the pathophysiological mechanisms behind these two syndromes are distinct, their clinical manifestation may be similar; thus, impairing the clinician's role in distinguishing them. However, there are signs that, if categorised, could constitute a helpful tool for the clinician. Criteria assisting in the differentiation between syncope and generalised epileptic seizures are described below and summarised in table 2 and figure 1. 


\section{Precipitating events}

Precipitating events are those that can often trigger the episodes. In syncope, factors such as exercise, coughing, excitement or various stressful stimuli have been identified as trigger factors of the episode (Davidow et al., 2001, Bright et al., 1999, Calvert et al., 1996, Miller et al., 1999). Generalised epileptic seizures occur usually spontaneously (Davidow et al., 2001), mainly during sleep or rest (Carnes et al., 2006). There are, however, factors that have been described as potential triggers of generalised epileptic seizures, such as environmental stress (Carnes et al., 2006).

\section{Signs preceding the episodes}

Both syndromes may show signs prior to the main phase of the episode. In generalised epileptic seizures, there is the pre-ictal period which is not reported in syncope (Carnes et al., 2006, Wa, 2007, Strickberger et al., 2006, Ettinger, 1972, Davidow et al., 2001). However, sometimes the pre-ictal period may not be noticed in generalised epileptic seizures (Davidow et al., 2001). The duration of the pre-ictal period can last from minutes to days (Berendt et al., 1999).

In syncope, it is quite uncommon to have preceding signs (Davidow et al., 2001). If there are any, they might include weakness, ataxia, growling and symptoms derived from the autonomic nervous system such as urination and defecation (Davidow et al., 2001, Yee, 2010). The duration of these signs is a few seconds only (Yee, 2010).

\section{Signs that animals present during the main phase of the episode}

A syncopal episode is characterised by flaccid collapse (Bright et al., 1999, Heaven et al., 2000). In some occasions, though, the animal might not completely collapse (presyncope) (Lewis et al., 1999). Stiffness of the limbs and opisthotonus might occur, but are quite uncommon compared to generalised epileptic seizures. Tonic-clonic movements and rigidity of the limbs might occur during and after the episode (hypoxic convulsive syncope), which might be confounded with generalised tonic-clonic epileptic seizures (Ettinger, 1972, Folino, 2005, Jhanjee et al., 2006, Strickberger et al., 2006). In the latter, dogs experience tonic-clonic movements and contractions of the facial muscles, with loss of consciousness (Heaven et al., 2000).

In addition, urinary and faecal incontinence, as well as hyper-salivation may occur in both syndromes (Davidow et al., 2001, Skrodzki et al., 2008, Yee, 2010). Nonetheless, it has been reported that urinary and faecal incontinence (Heaven et al., 2000, Wa, 2007) and hyper-salivation (Yee, 2010) are more often associated with seizures.

\section{Duration of the main phase of episodes}

The duration of the two syndromes varies. Generalised epileptic seizures (ictus phase) can last from seconds to minutes, whilst syncope lasts only for a few seconds (Davidow et al., 2001). Generally, syncope occurs for a shorter period of time in comparison to seizures, although this in not always the case (Gompf, 2008). 
In epileptic seizures, ictus is followed by signs characteristic of the post-ictal phase. During this phase, dogs might lay motionless for a period of time (usually over ten minutes) appear blind, disoriented, and ataxic (Skrodzki et al., 2008). The duration of the post-ictal period might vary from minutes to hours, or even up to some days (Podell, 1996, March, 1998).

On the contrary, there are no such signs after a syncopal episode (Davidow et al., 2001, Heaven et al., 2000, Wa, 2007). Dogs with syncope generally do not experience any signs following the events, have a rapid recovery, and return to their normal pre-syncope stage very quickly (Yee, 2010, Kenny, 2002, Jhanjee et al., 2006, Folino, 2005, Ettinger, 1972, Strickberger et al., 2006).

In cases of neurocardiogenic syncope episodes, the period required for the dogs to regain normal consciousness might be prolonged (Yee, 2010). Rarely, dogs can present signs of confusion or very mild depression for a short period of time (Skrodzki et al., 2008).

\begin{tabular}{|c|c|c|}
\hline & Generalised seizures & Syncope \\
\hline Precipitating events & $\begin{array}{l}\text { Usually none; can occur during } \\
\text { sleep }\end{array}$ & Stress, exercise, excitement \\
\hline Signs preceding the episodes & $\begin{array}{l}\text { Signs related to the prodrome } \\
\text { and aura phases }\end{array}$ & $\begin{array}{l}\text { Usually none } \\
\text { Rarely acute weakness, ataxia, } \\
\text { vocalisation, urination and } \\
\text { defecation may occur }\end{array}$ \\
\hline \multirow[t]{3}{*}{$\begin{array}{l}\text { Symptoms that animals } \\
\text { present during the main } \\
\text { phase of the episode }\end{array}$} & $\begin{array}{l}\text { Motor activity such as tonic- } \\
\text { clonic, jaw and facial } \\
\text { movements }\end{array}$ & $\begin{array}{l}\text { Usually flaccid colapse; can be } \\
\text { rigid sometimes }\end{array}$ \\
\hline & $\begin{array}{l}\text { Urination and/or defecation, } \\
\text { hypersalivation }\end{array}$ & $\begin{array}{l}\text { Urination and/or defecation, } \\
\text { hypersalivation occur less } \\
\text { commonly }\end{array}$ \\
\hline & Unconsciousness & $\begin{array}{l}\text { Usually retains but may lose } \\
\text { consciousness }\end{array}$ \\
\hline $\begin{array}{l}\text { Duration of the main phase of } \\
\text { episodes }\end{array}$ & Usually longer (> 1 minute) & Usually shorter (< 1 minute) \\
\hline Signs following the events & $\begin{array}{l}\text { Signs related to post-ictal } \\
\text { phase, slow recovery }\end{array}$ & Usually none; rapid recovery \\
\hline
\end{tabular}




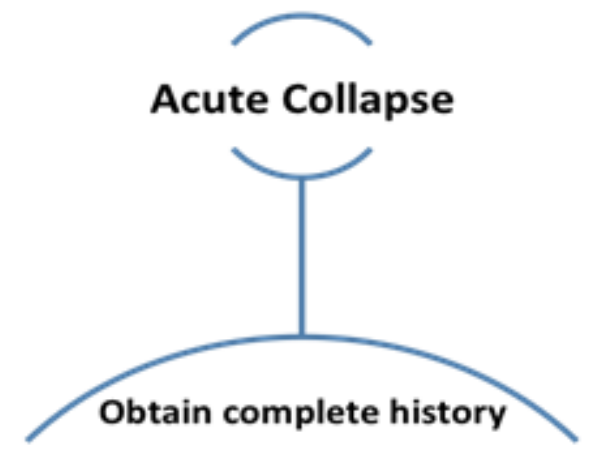

A. Signalment

B. Abnormal signs, such as neurological, respiratory or cardiovascular signs and exercise intolerance during and/or between the main episodes

C. Behaviour before and after the main episode

D. Disease progression

E. Medications

F. Potential exposure to toxins

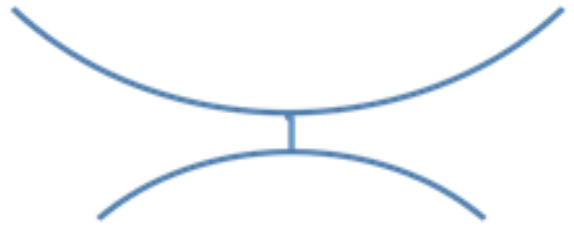

Describe the episode

A. Brief duration with rapid recovery and minimal or absent tonicclonic motor or autonomic activity and normal behaviour before and after the main episode

B. Preceding events such as exercise, excitement, coughing, vomitinng

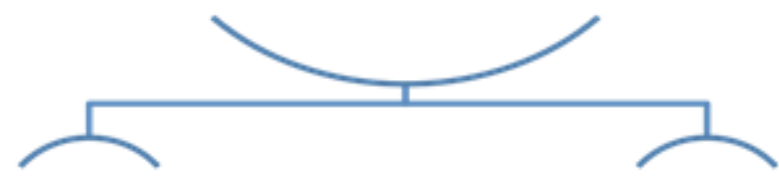

NO<smiles>C[C@@H]1C[C@H]2C[C@H]1C2</smiles>

Epileptic seizure

is more likely

\section{YES}

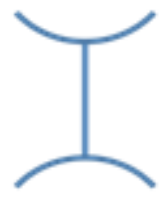

Syncope is more

likely
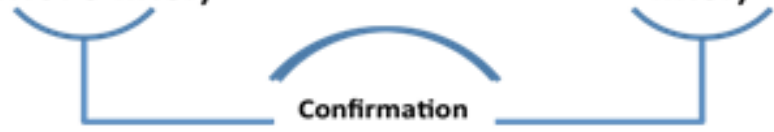

A. Complete general physical and neurological examination

B. Perform further diagnostic investigations

Figure 1: Algorithm for the clinical differentiation between generalised seizures and syncope. 
The clinical differentiation between syncope and generalised epileptic seizures is challenging. Same areas of brain affecting the level of consciousness are afflicted, but with different pathophysiological mechanisms being involved. Clinical criteria are very helpful for the differentiation of the two syndromes. Some of them may be considered more valuable than others as they could provide the clinician with more important clues. The presence of precipitating events (e.g. cough, exercise), motor activity during the episode, duration of the episode and signs following the events might be criteria of greater significance. On the other hand, signs preceding the episodes and autonomous nervous system signs might be considered as criteria of lesser importance. Although this review underlines the significance of clinical criteria for distinguishing epileptic seizures from syncope, definite conclusions are precluded due to the current weak evidence on this particular field. Therefore, original research studies are vital for establishing clinical criteria for the differentiation of these two syndromes.

CONFLICT OF INTEREST

The authors declare no conflicts of interest.

REFERENCES

1. Armijo, J. A. et al (2002) Advances in the physiopathology of epileptogenesis: molecular aspects. Revue Neurologique, 34 (5), pp. 409-29.

2. Aroniadou-Anderjaska, V. et al (2008) Pathology and pathophysiology of the amygdala in epileptogenesis and epilepsy. Epilepsy Research, 78 (2-3), pp. 102-116. DOI: 1016/j.eplepsyres.2007.11.011

3. Barnett, L. et al (2010) A retrospective study of 153 cases of undiagnosed collapse, syncope or exercise intolerance: the outcomes. Journal of Small Animal Practice, 52 (1), pp.26-

31. http://dx.doi.org/10.1111/i.1748-5827.2010.01013.x

4. Berendt, M. and Gram, L. (1999) Epilepsy and Seizure Classification in 63 Dogs: A Reappraisal of Veterinary Epilepsy Terminology. Journal of Veterinary Internal Medicine, 13 (1), pp. 14-20.

DOI: http://dx.doi.org/10.1111/i.1939-1676.1999.tb02159.x

5. Boothe, D. M. (2001) Anticonvulsants and other neurologic therapies in small animals. In: Small Animal Clinical Pharmacology and Therapeutics, Philadelphia, Elsevier Saunders.

6. Bright, J. and Cali, J. (2000) Clinical usefulness of cardiac event recording in dogs and cats examined because of syncope, episodic collapse, or intermittent weakness: 60 cases (1997-1999). Journal of the American Veterinary Medical Association, 216 (7), pp. 1110-1114.

DOI: http://dx.doi.org/10.2460/javma.2000.216.1110

7. Bromfield, E. Cavazos, J. and Sirven, J. (2006) Chapter 1, Basic Mechanisms Underlying Seizures and Epilepsy. In: Bromfield, E., Cavazos, J. and Sirven, J. (2006) An Introduction to epilepsy. West Hartford (CT), American Epilepsy Society., viewed 20 September 2016, <http://www.ncbi.nlm.nih.gov/books/NBK2510/>

8. Calvert, C. Jacobs, G. and Pickus, C. (1996) Bradycardia-Associated Episodic Weakness, Syncope, and Aborted Sudden Death in Cardiomyopathic Doberman Pinschers. Journal of Veterinary Internal Medicine, 10 (2), pp. 88-93. DOI:http://dx.doi.org/10.1111/i.1939-1676.1996.tb02034.x

9. Carnes et al. (2006) Management of Canine Idiopathic Epilepsy. Standards of Care Emergency and Critical Care Medicine, 8, pp.1-6.

10. Davidow, E.B. Woodfield, J.A. (2001) Syncope: Pathophysiology and differential diagnosis. Compendium on Continuing Education for the Practicing Veterinarian, 23, pp. 608-620.

11. Ettinger, A. J. (1972). Cardiac emergencies. Veterinary Clinics of North America, 2, pp.235-42. 
DOI: http://dx.doi.org/10.1016/S0091-0279(72)50028-X

12. Fisher, R. et al. (2005) Epileptic Seizures and Epilepsy: Definitions Proposed by the International League Against Epilepsy (ILAE) and the International Bureau for Epilepsy (IBE). Epilepsia, 46 (4), pp. 470-472. DOI: http://dx.doi.org/10.1111/j.0013-9580.2005.66104.x

13. Folino, A. (2005) Cerebral autoregulation in neurally mediated syncope: victim or executioner?. Heart, 92 (6), pp. 724-726. DOI: http://dx.doi.org/10.1136/hrt.2005.069179

14. Gompf, R. E. (2008)The history and physical examination. In: Tilley P.L., Smith Jr W.K.F., Oyaman A.M. Manual of Canine and Feline Cardiology, Saunders Elsevier.

15. Heaven, D. J. Sutton, R. (2000) Syncope. Critical Care Medicine, 28, pp. 116-20. DOI: http://dx.doi.org/10.1097/00003246-200010001-00002

16. Herman, S. T. (2006) Clinical trials for prevention of epileptogenesis. Epilepsy Research, 68, pp.35-8. DOI: http://dx.doi.org/10.1016/j.eplepsyres.2005.09.015

17. Jhanjee, R. et al. (2006) Syncope in Adults: Terminology, Classification, and Diagnostic Strategy. Pacing and Clinical Electrophysiology, 29 (10), pp. 1160-1169. DOI: http://dx.doi.org/10.1111/i.15408159.2006.00508.x

18. Kenny, R. A. (2002) Neurally mediated syncope. Clinical Geriatric Medicine, 18, pp. 191-210. DOI:http://dx.doi.org/10.1016/S0749-0690(02)00005-8

19. Lewis, D. and Dhala, A. (1999) Syncope In The Pediatric Patient: The cardiologist's perspective. Pediatric Clinics of North America, 46 (2), pp. 205-219.

DOI: http://dx.doi.org/10.1016/S0031-3955(05)70113-9

20. Lüders, H. O. et al. (2006) The epileptogenic zone: general principles. Epileptic Disorders, 8 Suppl 2, pp. 1-9. DOI: http://dx.doi.org/10.3109/9780203091708-114

21. March, P. (1998) Seizures: Classification, etiologies, and pathophysiology. Clinical Techniques in Small Animal Practice, 13 (3), pp. 119-131. DOI: http://dx.doi.org/10.1016/S1096-2867(98)80033-9

22. Miller, R. et al. (1999) Retrospective Analysis of the Clinical Utility of Ambulatory Electrocardiographic (Holter) Recordings in Syncopal Dogs: 44 Cases (1991-1995). Journal of Veterinary Internal Medicine, 13 (2), pp. 111-122. DOI:http://dx.doi.org/10.1111/j.1939-1676.1999.tb01138.x

23. Moya, A. et al (2009) Guidelines for the diagnosis and management of syncope (version 2009): The Task Force for the Diagnosis and Management of Syncope of the European Society of Cardiology (ESC). European Heart Journal, 30 (21), pp. 2631-2671. DOI:1093/eurhearti/ehp298

24. Packer, R. (2015) Inter-observer agreement of canine and feline paroxysmal event semiology and classification by veterinary neurology specialists and non-specialists. BMC Veterinary Research, 11 (1), p. 39. DOI: http://dx.doi.org/10.1186/s12917-015-0356-2

25. Podell, M. (1996) Seizures in Dogs. Veterinary Clinics of North America: Small Animal Practice, 26(4), pp.779-809.

26. Rogawski, M. (2005) Astrocytes get in the act in epilepsy. Nature Medicine, 11 (9), pp. 919920.DOI: http://dx.doi.org/10.1038/nm0905-919

27. Schnipper, J. and Kapoor, W. (2001) Diagnostic Evaluation and Management of Patients with Syncope. Medical Clinics of North America, 85 (2), pp. 423-456. DOI: http://dx.doi.org/10.1016/S00257125(05)70321-7

28. Skrodzki, M. and Trautvetter, (2008) Syncope in dogs-a syndrome, not a disease. Veterinary focus, 18 (3), pp. 36-46.

29. Strickberger, S. et al. (2006) AHA/ACCF Scientific Statement on the Evaluation of Syncope: From the American Heart Association Councils on Clinical Cardiology, Cardiovascular Nursing, Cardiovascular Disease in the Young, and Stroke, and the Quality of Care and Outcomes Research Interdisciplinary Working Group; and the American College of Cardiology Foundation: In Collaboration With the Heart Rhythm Society: Endorsed by the American Autonomic Society. Circulation, 113 (2), pp. 316-327. DOI: 10.1161/CIRCULATIONAHA.105.170274

30. Tidwell, A. and Robertson, I. (2011) Magnetic Resonance Imaging Of Normal And Abnormal Brain Perfusion. Veterinary Radiology \& Ultrasound, 52, pp.S62-S71. DOI: http://dx.doi.org/10.1111/j.1740$\underline{8261.2010 .01786 . x}$ 
31. Yee, K. (2010). Syncope. In: Ettinger JS and Feldman E.C. Textbook of Veterinary Internal Medicine. 7th ed. St. Louis, MO. Saunders Elsevier. pp. 275-77.

32. Wa, W. (2007). Syncope or intermittent collapse. In: Ware, W. (2007). Cardiovascular disease in small animal medicine. London: Manson/The Veterinary Press.

33. Waelbers, T. et al (2010). Brain perfusion part 1: regulation mechanisms and measurements of brain perfusion. Diergeneeskd. Tijdschr, 79, pp. 169-177. 


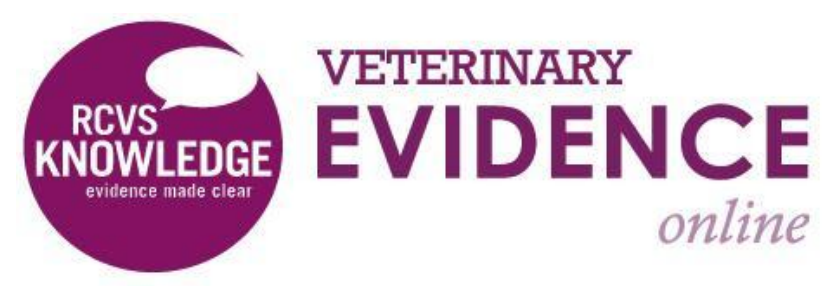

\begin{abstract}
Intellectual Property Rights
Authors of Articles submitted to RCVS Knowledge for publication will retain copyright in their work, but will be required to grant to RCVS Knowledge an exclusive license of the rights of copyright in the materials including but not limited to the right to publish, re-publish, transmit, sell, distribute and otherwise use the materials in all languages and all media throughout the world, and to license or permit others to do
\end{abstract} so.

Authors will be required to complete a license for publication form, and will in return retain certain rights as detailed on the form.

Veterinary Evidence and EBVM Network are RCVS Knowledge initiatives. For more information please contact us at editor@veterinaryevidence.org.

RCVS Knowledge is the independent charity associated with the Royal College of Veterinary Surgeons (RCVS). Our ambition is to become a global intermediary for evidence based veterinary knowledge by providing access to information that is of immediate value to practicing veterinary professionals and directly contributes to evidence based clinical decision-making.

www.veterinaryevidence.org

RCVS Knowledge is a registered Charity No. 230886. Registered as a Company limited by guarantee in England and Wales No. 598443.

Registered Office:

Belgravia House

62-64 Horseferry Road London SW1P 2AF

This work is licensed under a Creative Commons Attribution 4.0 International License. 